\title{
Diagnosing allergy in primary care: are the history and clinical examination sufficient?
}

Diagnostic testing is often crucial to securing a diagnosis, but it must be undertaken in a considered manner since there are time and cost implications and-particularly if invasive-the risk of adverse events. Allergic diseases are a common and increasing problem in Western societies [1], the commonest manifestations of which are dermatological and respiratory in nature, usually of mild or moderate severity. Less common problems include food, drug and insect venom allergy, which can be associated with severe or lifethreatening symptoms.

In contrast to the conclisions reached by Ahlstedt and Murray in this menthes Primary Care Respirato y tourno. [27, there is good eviderCe.

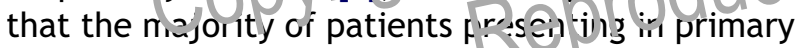
care with suspected allergic disorders can be managed without formal identification of the specific allergen trigger. This is a function of three factors: first, the pre-test likelihood of correctly diagnosing or excluding an allergic disorder is high if appropriate clinical questions are asked [3]; second, existing common therapeutic options for managing allergic problems are relatively safe; and third, there is insufficient evidence from randomised controlled trials to support current approaches which attempt to avoid aero-allergen exposure [4-6]. The position is more complex for the smaller numbers of patients who exhibit more serious potentially life-threatening systemic allergic reactions in response to food, drug and venom exposure.

Rhinitis is one of the most common manifestations of allergic disease [7], and treatment is rarely allergen-specific, the most effective treatment being a combination of antihistamine and topical anti-inflammatory drugs
[8]. The probability of rhinitis symptoms being allergic in nature is significantly increased if symptoms are triggered by animals or pollen, or if the patient has a personal history or a family history of allergy [3]. The need for a diagnostic test should therefore depend on whether or not the identification of an allergen trigger will influence the treatment decision. Given the challenges in avoiding exposure to these allergernitityers, there is in most individua's Vit to merit in identifying the underl, allergenic trigger. Empirical eatnerit is thereforeljustified as an initial step for rhinitis palenterich a convincing history of aitergy:

In contrast, if allergen avoidance is both effective and possible (as in the case of food or drug allergy) or an allergen-specific treatment such as immunotherapy $[9,10]$ is being considered, then identification of the specific allergen trigger is essential; although again, accurate history taking is of primary importance in establishing the role of allergy and interpreting test results. The medical history, related to the nature and timing of the symptoms, trigger factors, and evidence of personal and family history of allergic disease, should guide the need for, and choice of, diagnostic test [3].

In community settings, both skin prick tests and blood tests are available to identify lgE-mediated disease, although neither is commonly used. In food allergy, diagnostic cut-off levels for skin prick tests and specific IgE tests have been developed $[11,12]$ and are usefully discussed by Ahlstedt and Murray [2]. These cut-offs can be used to predict the likelihood of developing symptoms on exposure and may obviate the need for costly and time-consuming food challenges. There is a 
relatively good correlation between skin prick tests and blood tests [13], and so the choice of test is likely to be based on the nature of the symptoms, safety, availability of extracts, costs, and operator expertise in the interpretation of results.

Skin prick tests are simple (although relatively time-consuming) and results are visible and available immediately. Safety still appears to be a major concern, although the procedure is well tolerated by patients and by nurses performing the tests in primary care [14], and anaphylaxis following skin prick tests to common aero-allergens has not been reported [15]. Skin prick tests for foods are less reliable than those for aeroallergens, resulting in a high rate of false positives [16]. Skin prick tests for foods, drugs and insect venom carry a risk of systemic reactions [15] and should only be performed by staff who are trained to recognise and treat them promptly and efficiently.

Measurement of allergen-specific IgE (slgE) antibodies present in the serum is an alternative and comparably reliable way of diagnosing atopy when skin prick tests are not available [17]. They are a particularly useful test for allergens which carry the risk of adverse reactions if used as a skin prick test (e.g. food allergens, venom, penicillin). Specific IgF testing (ap usually be arranged via the lofol biocinemistry/pathology laboratory. Revurest ing a cotal IgE leve! is rot a reliable iricicato of atopic siats and cannot be used diagnostically.

In terms of cost, skin prick tests appear to be the cheaper option, although the comparative costs of skin prick test solutions/sterile lancets and slgE blood tests should take into account a number of factors including the number of allergens needed, the longevity and stability of the test solutions, the cost per test, (including nurse time for skin prick testing), and the cost and availability of phlebotomy services. Specific IgE blood tests become more cost-effective compared to skin prick tests when testing for allergens such as foods, venoms or drugs which are used less frequently and which substantially increase the skin prick testing cost per test.

In summary, empirical treatment using evidencebased guidelines appears to be justified as an initial step for most patients with a convincing history of eczema, rhinitis and asthma in whom aero-allergen triggered disease is suspected. In the majority of such cases, diagnostic investigation will be reserved for those in whom there is genuine diagnostic uncertainty, where possibly inappropriate allergen avoidance regimens are being tried, or in whom immunotherapy is being considered. Sensitivity to foods, drugs, occupational allergens and insect venom can often be identified from the clinical history, but the diagnosis should be confirmed by an objective measurement of slgE if avoidance measures are possible or an allergen-specific treatment is available. Identification of slgE should precede referral for a specialist allergy opinion in patients in whom there is diagnostic uncertainty or those for whom allergen-specific therapy is being considered, as well as those patients who have potentially life-threatening symptoms, or-particularly in children-concomitant food allergy and asthma.

\section{References}

[1] Strachan DP, Sibbald B, Weiland SK, Ait-Khaled N, Anabwani $\mathrm{G}$, Anderson HR, et al. Worldwide variations in prevalence of symptoms of allergic rhinoconjunctivitis in children: the International Study of Asthma and Allergies in Childhood (ISAAC). Pediatr Allergy Immunol 1997;8:161-76.

[2] Ahlstedt S, Murray C. In vitro diagnosis of allergy: how to interpret lgE antibody results in clinical practice. Prim Care Resp J 2006;15(4):228-36.

[3] Gendo K, Larson FP. Evicionce-h-sea diagnostic strategies for eval deting slcpected allergic rhinitis. Ann Intern Med 20(4) 14J(4):278-89.

[4] Sheikh A, Hurk t $-B$ louse dust mite avoidance measures for pe e hial il ersic rhinitis. Cochrane Database Syst Rev (). (1): (4):CD001563.

[5] Gotzsche PC, Johansen HK, Schmidt LM, Burr ML. House dust mite control measures for asthma. Cochrane Database Syst Rev. 2004; (4):CD001187.

[6] Hoare C, Li Wan Po A, Williams H. Systematic review of treatments for atopic eczema. Health Technol Assess 2000;4(37):1-191.

[7] Bauchau V, Durham SR. Prevalence and rate of diagnosis of allergic rhinitis in Europe. Eur Resp J 2004;24:75864.

[8] Weiner JM, Abramson MJ, Puy RM. Intranasal corticosteroids versus oral $\mathrm{H}_{1}$-receptor antagonists in allergic rhinitis: systemic review of randomised controlled trials. Brit Med J 1998;317:1624-9.

[9] Walker SM, Pajno G, Torres Lima M, Wilson DW, Durham SR. Grass pollen immunotherapy for seasonal rhinitis and asthma: A randomised controlled trial. J Allergy Clin Immunol 2001;107:87-93.

[10] Malling HJ, Weeke B. Immunotherapy. Position Paper. Allergy 1993;48:1-35.

[11] Sampson HA. Utility of food-specific IgE concentrations in predicting symptomatic food allergy. J Allergy Clin Immunol 2001;107:891-6.

[12] Hill DJ, Heine RG, Hosking CS. The diagnostic value of skin prick testing in children with food allergy. Paed Allergy Immunol 2004;15:435-41.

[13] Williams PB, Dolen WK, Koepke JW, Selner JC. Comparison of skin testing and three in vitro assays for specific IgE in the clinical evaluation of immediate hypersensitivity. Ann Allergy 1992;68:35-45.

[14] Sibbald B, Barnes G, Durham SR. Skin prick testing in general practice: a pilot study. J Adv Nurs 1997;26:537-42. 
[15] Reid MJ, Lockey RF, Turkeltaub PC, Platts-Mills TAE. Fatalities from immunotherapy and skin testing. J Allergy Clin Immunol 1990;85:180.

[16] Sampson HA, Albergo R. Comparison of the results of skin tests, RAST, and double-blind placebo-controlled food challenges in children with atopic dermatitis. J Allergy Clin Immunol 1984;74:26-33.

[17] Witteman AM, Stapel PO, Perdok GJ, Sjamsoedin DHS, Jansen HM, Aalberse RC. The relationship between RAST and skin test results in patients with asthma or rhinitis: a quantitative study with purified major allergens. J Allergy Clin Immunol 1996;97:16-25.

Samantha Walker* Director of Research, Education for Health, Co-Chair, Primary Care Allergy Network, Senior Lecturer (Hon.), Division of Community Health Sciences: GP Section, University of Edinburgh, UK
Chris Morton

Co-Chair, Primary Care Allergy Network, The White House Surgery, Moreton-in-Marsh, Gloucestershire, UK

Aziz Sheikh

Professor of Primary Care Research and Development, Division of Community Health Sciences: GP Section, University of Edinburgh, UK Research Advisor, Education for Health

* Corresponding author. Education for Health, The Athenaeum, 10 Church Street, Warwick CV34 4AB,

UK. Tel.: +44 (0) 1926 838975; fax: +44 (0) 1926493224 . E-mail address: s.walker@educationforhealth.org.uk (S. Walker)

Available online at www.sciencedirect.com $\because$ ScienceDirect Available online at http://www.thepcri.com
Copyright General Practice Airways
Reproduction prohibited 